\title{
Service quality in dentistry: the role of the dental marse
}

\author{
This From the archive article by M.T. Mindak was originally published in the
} BDJ on 23 November 1996 (181: 363-368). Were dental nurses well motivated and satisfied with their roles 21 years ago? Did dentists' and dental nurses' perceptions of the dental nurse's role differ? Was there good communication within dental teams? Read on and see how 1995/6 compares to your experience in 2017.

Patients judge the dental service they receive by the interaction with the service providers - the dentist and his or her staff - as they are unable to judge the technical quality of the service. To perform well as a service provider, employees such as dental nurses have to be well motivated and satisfied with their position. A study of the role of the dental nurse in contributing to service quality in dentistry was carried out through interviews with dentists and nurses at 20 dental practices in the South Thames region in 1995. The results revealed that while dental staff believed that the role of the dental nurse was important in terms of the patient's view of the practice, perceptions of the nurse's role differed. The majority of dentists felt that the nurse's role should be to anticipate their needs, while the nurses' opinions were evenly divided between putting the needs of the patient first or those of the dentist. Nurses also felt that their role was stressful and reported a lack of praise and recognition of their efforts by dentists. Few practices had written contracts or performance appraisals. The results indicated a lack of effective communication in many dental practices, producing role strain for the nurse and reducing job satisfaction. Increasing job satisfaction reduces staff turnover, resulting in more consistent service quality and reducing associated costs. In order to achieve this, several recommendations are made with the aim of improving communication between staff in dental practices.

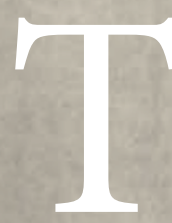

he actions of health care representatives play a critical role in the public perception of any health care service. The provision of dental treatment provides a good example of this as a patient cannot judge the technical aspects of dentistry and so will judge the quality of the service provided by the quality of the interaction with the service providers - the dentist and his or her staff.

The dental nurse is an essential member of the dental team. The dentist and dental nurse need to have a clear understanding of their working relationship and the factors that affect it, in order to be effective in the process of service delivery. The importance of an effective interaction between dentist and dental nurse is further highlighted by the fact that there is a possibility, albeit rare, of that interaction working to save the life of a patient who has been taken ill during treatment.

The real benefit, however, in developing an improved working relationship between dentist and nurse, is in creating a more harmonious working environment. This, in turn, produces a more pleasant, friendly atmosphere for the patient, who perceives an improvement in the quality of service. As a result, the patient is more likely to stay with the practice and recommend it to friends and family.

There is a high turnover of dental staff. ${ }^{1}$ This causes problems in delivering consistent service quality due to the disruption of routine for the dentist and loss of relationship continuity for patients when a staff member leaves. There is also the expense and time required to recruit and train a new member of staff. It is useful, therefore, to know what factors affect this turnover in order to try to reduce it. The aim of this study was to examine aspects of the role of the nurse in order to provide recommendations for reducing staff turnover and improving service quality in dental practices.

\section{Materials and methods}

A study was conducted by means of a series of qualitative interviews with dentists and nurses at 22 practices selected from the South Thames Health Authority region. Qualitative research was deemed to be the most appropriate

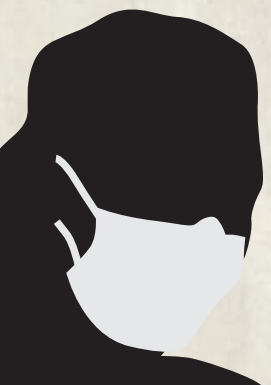


method as the study was to be exploratory in nature, to ascertain general themes, which required a more flexible approach than would be possible by a standardised structured questionnaire.

It was decided to select $11 \mathrm{NHS}$ practices and 11 private practices for the purposes of the study. The practices were chosen from three FHSAs from within the South Thames Health Authority region: Lambeth, Southwark and Lewisham FHSA, Bromley FHSA and Bexley and Greenwich FHSA. One hundred dental practices were initially selected, 50 practices from the NHS and 50 private practices.

Each practice was contacted by letter detailing the nature of the research. They were each then telephoned and asked if they wished to participate. Many practices did not wish to participate or else stated that the dates during which the study was being held (June to August 1995) were not convenient. The final sample of 22 practices (11 NHS and 11 private) was therefore, in part, self-selected.

The only selection criteria applied by the author were those of the practice being in one of the three FHSA areas, that the practice agreed to participate and that the interviewees consisted of one dentist and his or her own dental nurse and not a nurse who routinely worked with a colleague.

Pilot interviews were carried out at two additional dental practices in the London

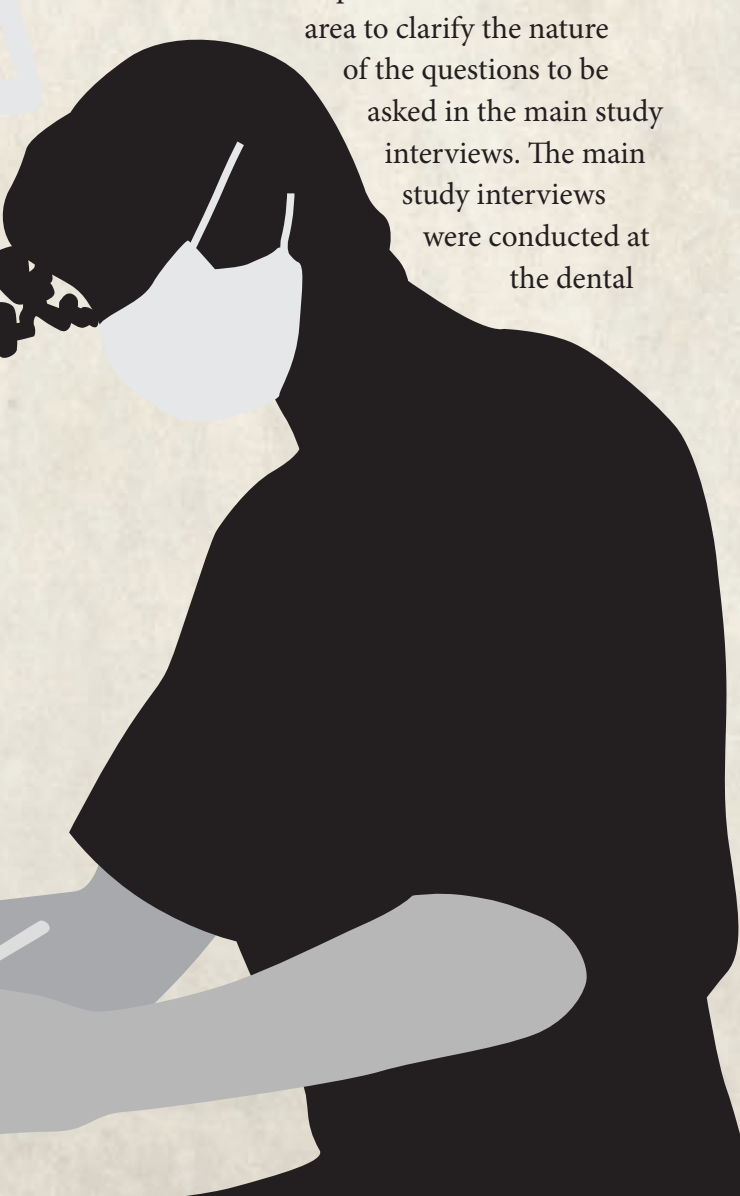

practices during July and August 1995. The vast majority took place during the practice lunch break and consisted of individual semistructured interviews of approximately 20 to 30 minutes.

The interviewer first asked general closed questions regarding qualifications, hours worked and so on and then asked openended questions regarding the role of the dental nurse. Two sets of questions were used for the interview frameworks - one for the dentists and one for the dental nurses, but both followed the pattern of closed followed by open-ended questions. The interviews were conducted face-to-face with the author who travelled to each practice. was from 27 to 58 years, with the majority between 30 and 40 years old. Four of the 20 dentists were female.

\section{DATE OF DENTAL QUALIFICATION}

The date of the dental qualification was naturally correlated with age and ranged from 1963 to 1991 . Ten of the UK's 16 dental schools were represented, from all parts of the country. Two respondents had trained abroad - Nigeria and India.

\section{TIME AT CURRENT PRACTICE}

Time at current practice ranged from 11 months to 32 years, with 12 respondents being at the practice for more than two years. The majority of

\section{'THE VAST MAJORITY OF THE DENTISTS}

VIEWED THE ROLE OF THE DENTAL NURSE

\section{PRINGIPALLY TO BE ANTICIPATING THE DENTIST'S}

\section{NEEDS: HAVING INSTRUMENTS READY, THE}

\section{SURGERY CLEAN AND SO ON.'}

The dentist and his or her nurse were interviewed separately and encouraged to speak freely, being assured that the other members of the practice would not be informed of any comments made. All interviews were taperecorded with individuals being informed of this prior to the interview and consent obtained. The taped interviews were then transcribed for analysis. Recurring themes and topics were then grouped together to produce the results.

\section{Quantitative results}

One dentist and his or her dental nurse were interviewed at each practice, a total of 40 individual interviews out of a possible 44 . The results from two practices, ie four interviews, were deemed unsuitable for inclusion in the study. The reasons for this were that for one practice there was a mechanical fault with the tape recorder resulting in only half the interview being recorded, and in the other practice, the dentist concerned declined to continue with the interview and did not wish to answer the questions. This left a final sample of 20 practices - 10 NHS and 10 private.

\section{Characteristics of the sample: dentists AGE AND GENDER The age range of dentists}

respondents were the practice owner and would therefore be expected to remain at the practice.

\section{NUMBER OF STAFF AT THE PRACTICE}

The number of staff was calculated to include part time staff as well as full time. The range was from two, where the nurse was also the full time receptionist (three practices), to one practice of 24 staff. The majority had four to six staff.

\section{NUMBER OF PATIENTS SEEN PER DENTIST PER DAY}

For NHS practices, this ranged from 18 patients (in two newly established practices) to around 40. The vast majority were in the range $25-30$. In private practices the figures were rather lower; the range was 10-25, with most being around 15 .

\section{Characteristics of the sample: nurses \\ AGE}

The range was from 16 to 57 years old. Two were over 50 , three in their 40 s and the remainder 39 or under. Two were teenagers. The average age of nurses in private practice was around nine years older (35 years) than that for NHS practices (26 years).

LENGTH OF TIME WORKED AS A DENTAL
NURSE
This varied from eight months to, in one case,
39 years (the nurse having left school at 14).


The sample was fairly evenly split between those who had worked as a nurse for 10 years or less and those who had worked as a nurse for more than 10 years.

\section{TIME AT CURRENT PRACTICE}

For NHS practices, this ranged from two days to six years. Seven out of 10 nurses had been at the practice for two years or less. In private practice, the range was from 10 months to 15 years. Five nurses had been at the practice for two years or less and the other five for two years or more.

\section{DENTAL NURSING CERTIFICATE}

Six out of 20 nurses had a qualification, five in private practice and one in the NHS. Two further nurses in the NHS had taken the exam and failed, but did not intend to retake it. Two nurses in private practices were currently on the training course.

\section{Qualitative results}

All those involved in the study agreed that the role of the dental nurse was very important in terms of how the patient viewed the practice. The nurse was seen to be the patients' confidante and provided reassurance:

'It's always you they will ask' (nurse aged 25, private practice)

'If they've got a problem, I talk to them because at times they don't want to talk to the dentist, so they talk to me and I can pass the message on to the dentist' (nurse aged 30, NHS practice)

The study also produced other findings that can be grouped into three areas:

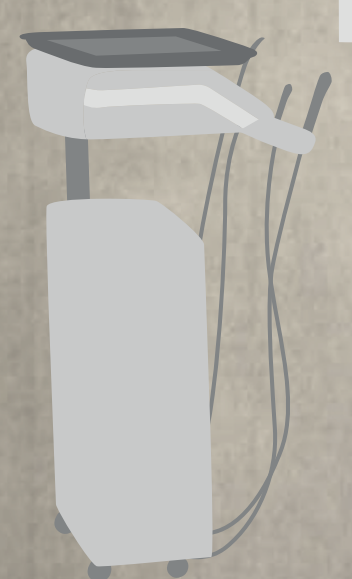

1. A difference in perceptions of the role of the dental nurse between nurses and dentists.

2. The lack of appreciation and acknowledgement of nurses' efforts by dentists, as felt by nurses.

3. The lack of formalisation of the nurse's role in terms of written contracts or performance appraisal and the lack of regular staff meetings.

\section{The difference in perceptions of the nurse's role \\ THE DENTISTS'VIEW}

The vast majority of the dentists (18 of 20) viewed the role of the dental nurse principally to be anticipating the dentist's needs: having instruments ready, the surgery clean and so on. They wanted the nurse to be able to think ahead for them:

'You get to a stage where she's got it ready before you say anything and then when you get one stage further, you can ask for the wrong things and get the right things' (male dentist aged 47 , private practice)

Dentists felt that reliability was very important in fulfilling the nurse's role:

'I've had situations where after being her for three or four months a nurse has taken her pay cheque on the Friday and then not come in on the Monday, without telling me that they're not coming back' (dentist aged 31, NHS practice)
Many of the dentists, 12 of 20, expressed a preference for older nurses rather than teenagers, and for those who had gained previous experience, saying that they found younger staff to be far less reliable in terms of timekeeping and attendance:

'If I had a choice of someone to employ, I would happily go for someone in their late 20 s onwards with children. We've found that with younger women, their attendance can be distinctly "iffy" and the merest sniffle, they're off' (dentist aged 39, private practice)

Dentists also felt that an empathetic and cheerful personality was important, not just for patients' sake, but also for their own morale. All dentists said that an efficient and friendly nurse acted to greatly reduce the day to day stress of practice:

'If you've got a very close relationship with that person (the dental nurse) for eight hours a day and if they're not happy it can drain on you and affect the relationship with the patient' (female dentist aged 30, NHS practice)

'My stress level goes up enormously if she isn't working with me ... she makes life a lot easier without a doubt' (male dentist aged 35, private practice)

\section{THE NURSES'VIEW OF THEIR ROLE}

In contrast to the dentists, dental nurses were divided as to their principal role: 10 nurses clearly stated that the patient was their first priority, while the other 10 said that the dentist's needs come first.

'My role is actually thinking for the dentist' (nurse aged 30, NHS practice)

'I think for him, I'm one step ahead' (nurse aged 31 private practice)

'To help the patient feel as relaxed as possible' (nurse aged 18, NHS practice)

'Primarily, to make sure the patients feel comfortable and welcome' (nurse aged 43 , private practice)

Nurses also said that they saw a major part of their role to be acting as an intermediary between dentists and patients and that this could be very stressful. They said that patients saw them as representing the practice and would want explanations as to why an appointment was late, for example, while the dentists would be telling them to go out and keep the patient calm:

'They (patients) quite often treat the nurse very differently to the dentist

... the patients have a real moan and then go into the surgery and be as nice as pie and you think "oooh"!' (nurse aged 22, private practice) 


\section{The lack of appreciation}

Many nurses, 11 of 20, reported problems in communicating with dentists. Areas of concern were principally the lack of definition of the nurses' role by dentists and lack of appreciation by dentists for the nurses' efforts. Nurses reported being given little instruction atmosphere in the practice, which, nurses said, was noticed by the patients:

'If the dentist appreciates what the nurse is doing, then the nurse gives her best to the dental surgeon. You've got to work as a team ... if you work as a team and you can be friends then the patient gets so much more out of that

'MOST NURSES, 14 OF' 20, REPORTED BEING SPOKEN

TO IN A DEROGATORY MANNER, WHICH THEY

\section{FELT INDICATED A LACK OF RESPECT. THIS GOT}

\section{WORSE WHEN THE DENTIST WAS UNDER STRESS.'}

when joining a practice and were often expected to know what to do in the surgery:

'He just expected everything there without telling you or asking you. Me sitting there not doing it because I don't know what he needs and him probably thinking, "Oh she's just sitting there", but it's not, it's because he's not actually explained what he needs and therefore I can't mix it when I don't know' (nurse aged 24, NHS practice, describing life as a trainee at 17)

Most nurses, 14 of 20, reported being spoken to in a derogatory manner, which they felt indicated a lack of respect. This got worse when the dentist was under stress. Many understood that dentistry was stressful and wanted to help the dentist, but still wished to be spoken to courteously.

'He was very rude, he used to swear at you and abuse you if you did things wrong' (nurse aged 31 , private practice)

'I was a trainee and he was just very impatient and used to be sarcastic in front of patients and I didn't like that because it made me look stupid' (nurse aged 22, private practice)

Some dentists apparently coped with stress in unusual ways:

'There was one guy, if he didn't like things or things didn't go his way or he couldn't get a matrix band on, he'd throw tweezers at your ankles... It wasn't anything to do with the nurses, it was just his own pure frustration, but he was quite well known for it' (nurse aged 43, private practice)

Dental nurses wanted their efforts recognised and acknowledged by the dentist and felt that this rarely occurred. When this did happen, it was much appreciated and was felt to contribute to a more pleasant because the atmosphere is so different. I think a patient can feel an atmosphere when they go into a surgery. If they feel a good atmosphere, then they get good vibrations and they relax more' (nurse aged 44, NHS practice)

A nurse with 24 years' experience said of her employer, a dentist aged 39 , in private practice:

'I think really a dentist should include their nurse in the work or they can make them feel just like the washer-upper and I feel very included here ... he's terrific, absolutely terrific. This dentist will at the end of the day say "thank you". That's not usual, normally they're tools down and gone and leave you to clear up'.

Some dentists said they found managing staff difficult, especially in the first years of practice. Three of the four female dentists felt that the task was harder as a woman than for a man. Their nurses felt that female dentists were more sensitive in dealing with staff and would help the nurse more than a male dentist would.

\section{RESPONSIBILITY AND EXPANSION OF THE ROLE OF THE DENTAL NURSE}

At present, the role of the dental nurse is limited in terms of direct clinical interaction with the patient, in contrast to other countries such as the USA and New Zealand. Dentists and nurses were asked their views on the possible expansion of the nurse's role, as considered in the Nuffield Report. ${ }^{2}$

Most dentists, 11 of 17 (three did not respond), were not in favour of the dental nurse taking on any clinical duties, apart from taking radiographs. Many did not see any real benefit of the nurse undertaking these tasks and expressed concern about the level of training for nurses that would be necessary to ensure patient safety. The majority of nurses however, expressed a desire to expand their role and mentioned the lack of a career path. Several nurses mentioned that being given responsibility made their job more enjoyable:

'Having the responsibility brings our your best qualities because everybody's got a forte at something' (nurse aged 31, private practice)

Six of the 20 had a dental nursing

qualification, and five of these were in private practice. Many expressed a desire to expand their role with the patient and said they felt frustrated at not being able to do more in the surgery. Five of the 20 interviewed had made a definite decision to obtain further qualifications towards that end and had registered to train as a hygienist (1), dental therapist (2) oral health educator (1) and general medical nurse (1).

\section{SALARY}

Four of the 20 nurses brought up the subject of their salary. They felt it was far too low for the job and felt unappreciated as a result. One nurse said:

'You are risking yourself as much as dentists, with AIDS and all that, and their pay is good

that makes me sick ... they sort themselves out and forget the nurses' (nurse aged 24, NHS practice)

Some dentists seemed to be unaware of just how sensitive an issue this was. Nurses in private practice, not surprisingly, reported being paid more than in NHS practices and had left NHS practices as a result. Some private dentists said that they felt higher salaries to be a worthwhile investment to attract good staff.

\section{The lack of a formalised role WRITTEN CONTRACTS AND STAFF APPRAISAL}

Only five practices in the survey had a written contract for staff and only one carried out a formal staff appraisal. Nurses said that they would welcome a regular appraisal of their performance, as some had just occasional comments made to them. Several complained of being readily criticised if they made a mistake, yet never praised when they performed well.

\section{PRACTICE MEETINGS}

Similarly, only five practices held practice meetings on a regular basis, while a few more held them on an occasional basis. The practices that did currently hold meetings found them to be valuable aids to communication and staff participation. Some nurses however, felt that little was achieved by meetings: they had attended them in the past 
and said that little attention was paid to their opinions or suggestions. In a lot of practices, both dentists and nurses did not see any need for meetings at all.

\section{Discussion}

The results of the study should be interpreted with caution as this was a small and selfselecting sample. Nonetheless, several of the findings are relevant to dental practice management. It was evident from the study that there are problems in communication between the dentist and the dental nurse in many dental practices. These problems were manifested in the different perceptions as to what the role for the nurse actually entailed, in the way the required role was explained, the lack of written job descriptions, coupled with little positive feedback or appraisal, and a derogatory manner used in addressing the nurse. In addition, very few practices provided an opportunity for the nurse to raise problems, make suggestions or participate in decision making, by means of mechanisms such as a regular practice meeting. The lack of management skills training for dentists may well be a contributory factor here. These findings confirm previous research that
Table 1 Achieving better communication

- The aim should be to give praise and encouragement to staff straight away, even for a small effort, as it will be appreciated.

- The dentist should hold an informal conversation with their dental nurse to discuss her role and any areas of the working relationship that may be causing concern. This is an ideal situation in which to use active listening. The aim should be to stress how important her role is in terms of the patient's perception of the practice.

- To deal with behaviour that needs to be changed, the dentist should discuss with the nurse why it is necessary to change and how it should be changed. This should be done in a positive way by giving encouragement and praise, and setting realistic goals.

Table 2 The practice meeting

- A practice meeting with all staff should be conducted to discuss improving communication in the practice. Participation with ideas and suggestions should be encouraged.

- Regular practice meetings should be established thereafter, for example, once a fortnight, as an opportunity for staff to discuss problems and contribute ideas for managing the practice.

- To deal with behaviour that needs to be changed, the dentist should discuss with the nurse why it is necessary to change and how it should be changed. This should be done in a positive way by giving encouragement and praise, and setting realistic goals.

of communication between dentist and nurse could well be contributing to the high turnover rate. In order to reduce turnover of dental nurses and increase job satisfaction, positive steps should be taken to improve communication.

\section{Recommendations}

\section{INVESTMENT TO ATTRACT GOOD STAFF.}

has been carried out into job related for the dental nurse.

\section{The consequences of poor communication}

A lack of communication between and employer and employee results in several negative outcomes which researchers have found affect job satisfaction. ${ }^{6,7}$ Two principal ones are role ambiguity and role conflict. Role ambiguity occurs where a role has not been clearly defined and responsibilities are ambiguous, as was clearly felt by the nurses in the study. Role conflict occurs when the employee is expected to carry out contradictory tasks, such as trying to please both patient and dentist. The stress nurses mentioned at being the 'intermediary' is well recognised in the literature, this position being described as the 'boundary-spanning' role ie the boundary between the organisation and the customer. Such roles have been associated with high degrees of stress for employees.?
These factors result in role strain, which has been shown to decrease job satisfaction. Dentists stated that the main problems they had with dental nurses were poor timekeeping and absenteeism. Both these behaviours have been shown to be symptomatic of reduced job satisfaction

\section{Staff turnover}

A reduction in job satisfaction is directly related to the employee's tendency to leave the organisation. ${ }^{9}$ It is known that dental nurses have a high employment turnover, with the resultant increased costs and inconsistency of service quality for the dental practice as previously mentioned. Turnover of staff adversely affects the consumer's perception of the service, with the result that they will go elsewhere. So in order to provide and maintain service quality in the eyes of the consumer (the patient) staff turnover is to be avoided.

The results of this study show that a lack
The process of good communication involves the processes of active listening - concentrating on exactly what a person is saying, not jumping to conclusions or assumptions; feedback on how the role was performed helps to clarify discussion and self-disclosure - an atmosphere of trust and openness should be established so that staff feel able to make comments and suggestions. ${ }^{10}$

Many of the suggestions made below are not new. ${ }^{11-16}$ However, this survey shows that they are still relevant and that improving communication is still necessary for many dental practices. Several of these improvements can be made immediately and the majority can be implemented at little or no financial cost.

\section{Immediate changes in the} dental practice

To make changes towards improving communication in the dental practice work, it is best to start with small and simple things that are easy to implement and are likely to succeed. Early success will encourage staff and reinforce the new approach. 


\section{Table 3 Further clarify roles by written descriptions}

- Provide written contracts/job descriptions for all existing and new staff.

- When interviewing for new staff, ensure that the description of the expected role is accurate and detailed, so that new employees have realistic expectations of the role.

\section{Table 4 Build in praise and recognition by:}

- Conducting regular formal staff performance reviews eg two or three times a year.

- Implementing an annual salary review - consider an increase/bonus system.

\section{Table 5 Training and delegation}

- Invest in training for all staff. Establish in which areas individuals would like to obtain more skills. Consider courses for the practice as a whole. such as in interpersonal and teambuilding skills.

- Consider areas in the practice for which individual staff can be solely responsible, and delegate appropriate tasks and responsibilities (after ensuring that they have the necessary information and training to carry them out).

- Build a sense of identity with the practice: consider formal job titles, uniforms and business cards.

\section{ACHIEVING BETTER COMMUNICATION}

Praise and recognition are powerful 'motivators'. These are therefore ideal areas with which to start (Tables 1-5).

\section{THE PRACTICE MEETING}

Efforts to improve communication in the practice should involve all the staff, not just the nurse, and the suggestions below are relevant for all staff. In addition, practice meetings are a valuable tool.

\section{Changes in the medium term}

The initial approaches will start to improve communication in the practice and can be reinforced over the following few months by further measures - further clarify roles by written descriptions, build in praise and recognition and build up an atmosphere of trust by training and delegation.

\section{Long term changes -}

\section{recommendations for the profession}

As we can see, these are relatively simply changes that can be carried out in a short period of time. However, for the profession as a whole, there remains the issue of training for both dentists and nurses which needs to take into account communication and interpersonal skills, which, as the study showed, are so necessary. In addition, the recommendations in the Nuffield Report ${ }^{2}$ regarding the training of dental nurses, ie the introduction of a national training standard and statutory minimum qualification, should be implemented as soon as possible. A better career structure for dental nurses will act to retain and motivate staff, raise standards of care, improve service quality and thereby the patients' view of the practice.

1. Bader J. Auxiliary turnover in 13 dental offices. J Am Dent Assoc 1982; 104: 307-312.

2. Nuffield Report. Education and training of personnel auxiliary to dentistry. Norwich, UK: The Nuffield Foundation 1993.

3. Locker D, Burman D, Otchere D. Workrelated stress and its predictors among Canadian dental assistants. Community Dent Oral Epidemiol 1989; 17: 263-266.

4. Blinkhorn A. Stress and the dental team: a qualitative investigation of the causes of stress in general dental practice. Dent Update 1992; 19 : 385-387.

5. Craven R C, Blinkhorn A S, Roberts C. A survey of job stress and job satisfaction among DSAs in the northwest of England. $\mathrm{Br}$ Dent J 1995; 178: $101-$ 104.

6. Jackson $\mathrm{S}$ E, Schuler R S. A meta-analysis conceptual critique of research on role ambiguity and role conflict in work settings. Organizational Behaviour and
Human Decision Processes 1985; 36: 16-49.

7. Netemeyer R, Burton S, Johnston M. A nested comparison of four models of the consequences of role perception variables. Organizational Behaviour and Human Decision Processes 1995; 61: 77-93.

8. Shamir B. Between service and servility. Human Relations 1984; 33: 741-756.

9. Bedian A, Armenakis A. A path analytic study of the consequences of role conflict and ambiguity. Academy of Management J 1981; 24: 417-424.

10. Hellriegal D, Slocum Jr J, Woodman R W. Organizational behaviour. 6th ed. St Paul, MN: West, 1992.

11. Cummings T G, Worley C G. Organizational development and change. St Paul, MN: West, 1993.

12. Schwartz S. Motivating the dental staff. Dent Clin North Am 1988; 32: 35-45.

13. McKenzie S. Empowering your dental team. J Michigan Dent Assoc 1992; 74: 36-38.

14. Manji I. Fair pay and then some: how to retain your staff. J Can Dent Assoc 1992; 58: 895-896.

15. Butters J, Willis D. Satisfaction level of dental office personnel. Gen Dent 1993; May-June: 236-240.

16. Nacht E S. 13 ways to keep the staff

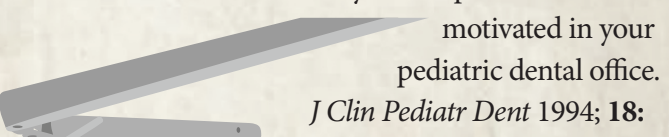
163-164. 